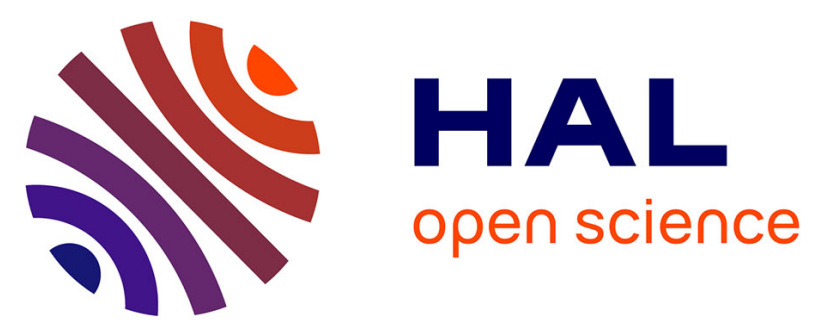

\title{
Assessing Management Perceptions Linked to a Flagship Species: A New Approach to Increase Landscape Management Legitimacy and Support
}

\author{
Lisa Ernoul, Angela Wardell-Johnson, Raphaël Mathevet, Alain Sandoz, \\ Olivier Boutron, Loïc Willm, Stephan Arnassant, Arnaud Béchet
}

\section{To cite this version:}

Lisa Ernoul, Angela Wardell-Johnson, Raphaël Mathevet, Alain Sandoz, Olivier Boutron, et al.. Assessing Management Perceptions Linked to a Flagship Species: A New Approach to Increase Landscape Management Legitimacy and Support. Coastal Management, 2021, pp.1-13. 10.1080/08920753.2021.1928456 . hal-03258900

\section{HAL Id: hal-03258900 https://hal.science/hal-03258900}

Submitted on 13 Dec 2021

HAL is a multi-disciplinary open access archive for the deposit and dissemination of scientific research documents, whether they are published or not. The documents may come from teaching and research institutions in France or abroad, or from public or private research centers.
L'archive ouverte pluridisciplinaire HAL, est destinée au dépôt et à la diffusion de documents scientifiques de niveau recherche, publiés ou non, émanant des établissements d'enseignement et de recherche français ou étrangers, des laboratoires publics ou privés.

\section{(1) (1) $\$$}

Distributed under a Creative Commons Attribution - NonCommercial - NoDerivatives 44.0 


\title{
Assessing Management Perceptions Linked to a Flagship Species: A New Approach to Increase Landscape Management Legitimacy and Support
}

\author{
Lisa Ernoul ${ }^{a, b}$, Angela Wardell -Johnson ${ }^{c}$, Raphaël Mathevet ${ }^{\mathrm{d}, \mathrm{e}}$, Alain Sandoz ${ }^{\mathrm{a}, \mathrm{f}}$, \\ Olivier Boutron ${ }^{a}$, Loïc Willm ${ }^{a}$, Stephan Arnassant ${ }^{\mathrm{g}}$ and Arnaud Béchet ${ }^{\mathrm{a}}$ \\ ${ }^{a}$ Tour du Valat, Research Institute for the Conservation of Mediterranean Wetlands, Le Sambuc, Arles, France; \\ ${ }^{\mathrm{b}}$ UMR ESPACE, Aix-Marseille Université, Aix en Provence, France; ${ }^{\mathrm{C} C e n t r e ~ f o r ~ H u m a n ~ R i g h t s ~ E d u c a t i o n, ~ C u r t i n ~}$ \\ University, Perth, Australia; ${ }^{d}$ CEFE, CNRS, Univ Montpellier, Univ Paul Valéry Montpellier 3, EPHE, IRD, \\ Montpellier, France; ${ }^{\mathrm{e} I n s t i t u t ~ F r a n c ̧ a i s ~ d e ~ P o n d i c h e ́ r y, ~ U M I F R E ~} 21$ CNRS/MAE, Puducherry, India; 'UFR Sciences,

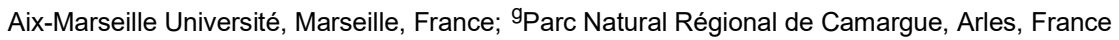

\begin{abstract}
Integrated socio-ecological decision-making is important in improving legitimacy in management decisions through effective solutions that avert conflicts. This research examined social perceptions in landscape planning and management with regard to the Greater flamingo, a flagship species along the southern French Coast. A strategic delivery to a cross-section in a social catchment $(n=87)$ captured the percep-tion and the recognition of management strategies through a survey questionnaire. Analysis was conducted through a multi-method approach, triangulating qualitative and quantitative results. Results show the importance of the attachment to flamingos in local land-scapes. Knowledge on flamingo ecology was relatively high and participants perceived some of the regional management options to be unfavorable for flamingos. Participants identified threats to the species and expressed concern for the future of the flamingos, chal-lenging the legitimacy of some landscape management decisions and planning policies. This research demonstrates the role of flagship species in stimulating reflection on landscape management, address-ing both the ecological and human dimensions. Understanding social perceptions of biodiversity management objectives is fundamental for effective coastal conservation.
\end{abstract}

KEYWORDS Camargue; environmental perceptions; flagship species; global changes; landscape management 


\section{Introduction}

Understanding how human populations perceive biodiversity management in the socio ecosystems they inhabit is fundamental for effective conservation (Ernoul and WardellJohnson 2014). Flagship species are charismatic symbols and are often used as key features in the promotion and justification of landscape management (Ducarme, Luque, and Courchamp 2013). Flagship species have been instrumental in raising awareness and promoting broader conservation policies (Smith and Sutton 2008; Runge et al. 2019; Senzaki et al. 2017). In the context of global change, socio-ecosystems are undergoing rapid and fundamental transformations across the world resulting in the gradual replacement of traditional uses (Turner 2010). As global conditions change, landscape structures and the dynamic requirements of flagship species are also expected to change over time (Maris and Bechet 2010). Exploring how flagship species are perceived by people in the landscape they inhabit may help to anticipate and adapt conservation policies and legitimize actions not only for the concerned species, but for landscape management as a whole.

The Greater Flamingo (Phoenicopterus roseus) is a flagship species for the Camargue (Rhone Delta) in southern France (Johnson and Cézilly 2007). Flamingos have bred and flourished in the Camargue for more than six centuries. In the 1960s, concerns were raised about a decrease in flamingo breeding in the Mediterranean basin with a risk of extinction of the west Mediterranean population. As a result, the Tour du Valat Institute in partnership with a salt company (SALINS Group) built an artificial breeding island in the Fangassier Lagoon, one of the saltpans of Salin-de-Giraud (Figure 1). The operation was a success, establishing a productive and growing flamingo population in the western Mediterranean basin (Béchet and Johnson 2007; Johnson and Cézilly 2007).

Recent changes in land ownership have disrupted traditional management of the flamingo breeding colony (Béchet et al. 2009; Béchet et al. 2012). The most immediate consequence was the total failure of flamingo breeding in the Fangassier Lagoon in 2007, 2014, 2016, 2017 and 2018. The failure in breeding can be partly explained by fluctuating water levels when water was no longer pumped for salt production and increased predation by fox and owls. A new breeding island was also successfully used in the saltpans of Aigues-Mortes (beyond the western limits of the Regional Natural Park of Camargue), acting as an alternative breeding site in 2014, 2017 and 2018.

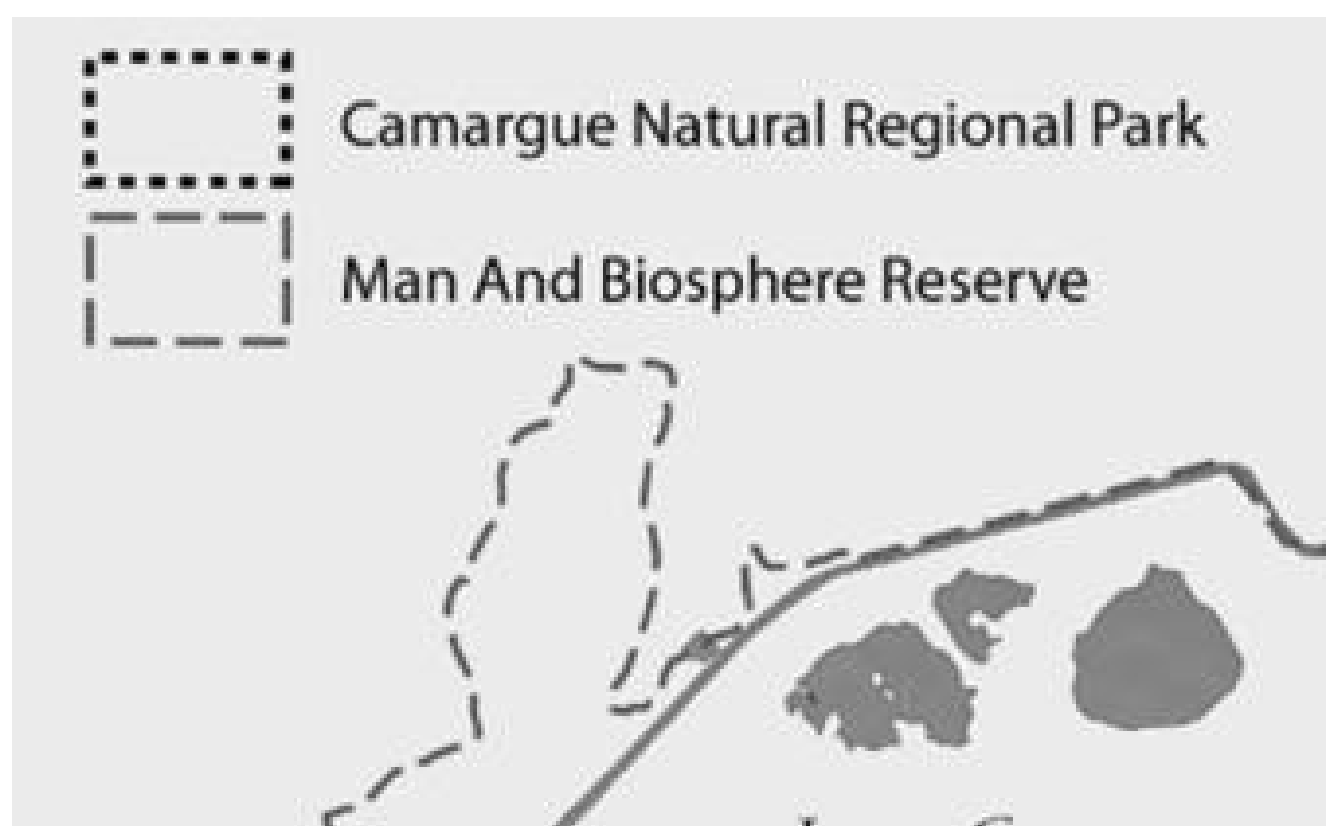


Figure 1. Location of the Camargue Natural Regional Park, workshop locations and flamingo breeding sites.

These changes raise new challenges regarding sound landscape management to maintain the presence of this flagship species in the Camargue. In turn, it becomes critical to understand local people's understanding and acceptance of different landscape management options in order to ensure the success of conservation policies. Given the favorable status of flamingo populations in the western Mediterranean basin and the damage the species causes to agricultural production (Ernoul et al. 2014), it is import-ant to evaluate the management actions that are needed to maintain a continual breeding flamingo population in the Camargue. It is also imperative to determine how these management actions can impact not only the flagship species, but influence other associated species and their ecosystems (Shen et al. 2020). We examine the perceptions that different Camargue stakeholders have of flamingos and the land management strategies that are implemented in the Camargue. The results of our survey are a practical guide for conservation managers to develop sustainable landscape management not only for the flagship species, but also for legitimizing the management actions within a given socio-cultural context.

\section{Material and methods}

\section{Study area and species}

The Camargue is one of the largest wetlands in the Mediterranean basin and benefits from significant national and international levels of protection (Mathevet, Tourenq, and Mesléard 2002; Ernoul, Mesléard, and Béchet et al. 2012). The Camargue has undergone important land-use changes over recent decades, impacting the habitats and species living and frequenting the area (Guillemain et al. 2015). Our study area was restricted to the perimeter of the Regional Natural Park of Camargue (PNRC; 100,000 ha), encompassing three communes: Arles, Saintes-Maries-de-la-Mer and Port-Saint-Louis-du-Rhône (Figure 1). The PNRC is managed in accordance with a charter based on sustainable development principles encompassing environmental, social and economic issues (http://www.parccamargue.fr/le_parc_organisme_public. html). Traditional socio-economic activities in the Camargue include salt production, rice farming, extensive grazing (bovine and equine), hunting and tourism (Mathevet 2004). Ecological research along with management and conservation of protected areas are also important job providers. There is one active saltpan in the PNRC that is privately owned and managed by the international salt company SALINS which also owns a saltpan in Aigues-Mortes (outside the limits of the PNRC, but within the perimeter of the UNESCO Biosphere Reserve that covers the whole Rhone River delta).

The Greater Flamingo is listed in Annex 1 of the Wild Birds Directive of the European Union (European Union 2009) and in Appendix II of the Bern Convention (strictly protected species) with a distribution range spanning from Africa to the Middle East and Southern Europe. Although the species is not globally threatened, it is considered vulnerable given its dependence on a limited number of wetlands for reproduction. Over the past 40 years, flamingos have begun foraging in rice fields in and around the PNRC causing variable but sometimes significant crop damage (Ernoul, Mesléard, and Béchet et al. 2012; Ernoul et al. 2014; Mathevet, Tourenq, and Mesléard 2002). 
Approximately half of the saltpans (5400 ha) including the flamingo breeding island in Salin -de- Giraud changed vesting in 2008 from private property regulated by com-mercial salt production to vesting as public land managed for coastal protection and biodiversity conservation when it was acquired by the Conservatoire du Littoral (the French Agency for Coastal Protection). The change in ownership has given way to the largest coastal restoration project in the Mediterranean basin. In addition, recent changes in farm subsidies from the European Union Common Agricultural Policy (CAP) have resulted in significant modifications in water management in the Camargue following a reduction of $25 \%$ of the rice surface area between 2002 and 2012 (Pernollet et al. 2015).

\section{Survey sample}

The diversity of land -uses and decision-making interests in the three communes of the PNRC required a comprehensive sampling involving both self-selection and invi-tation approaches to capture the breadth of environmental and socio-cultural heritage characteristics. This strategy has been extensively applied, tested and proved successful in representing the community in the Camargue (Ernoul and Wardell-Johnson 2015). The social strata analysis allowed us to identify gaps in response. The gaps were filled by applying three complementary approaches to the delivery of survey instruments: participatory workshops (self-selection), internet surveys (self -selection) and face-to-face survey delivery (invitation). The same questionnaire was used for all the partic-ipants regardless of the delivery approach. The participatory workshops were hosted by the PNRC in two villages: Salin-de-Giraud and Mas Thibert (Figure 1). Workshops were open to the general public (walk in participation) and included 8 participants from Mas Thibert and 11 from Salin-de Giraud (total of 19 participants). The work-shops began with an introductory talk by a local expert on flamingos (AB) followed by the completion of a selfadministered questionnaire. The introductory talk was used as a way to attract participation and discussion with the participants. The presentation included general information about flamingos and management in the Camargue and did not give specific information related to the questions in the questionnaire.

The internet surveys provided the opportunity for the general population to partic-ipate in the study outside the immediate influence of other respondents present in a workshop setting (Kahila and Kyttä 2009). Information on the internet survey was made available through Tour du Valat and the PNRC websites. A total of 42 people responded to the internet survey. The gaps in representation from geographic locations and socioprofessional groups were corrected through face-to -face survey delivery. The participants for the face-to face surveys were identified by first determining the geo-graphic locations and socio -professional groups that were underrepresented or not represented at all. We then contacted local experts in the area to suggest possible participants that could respond to the questionnaire. These candidates were then con-tacted by the project leader (LE) . The interviews took place either at the participant's place of work or at their home. Using these three delivery techniques, a total of 87 participants responded to the questaionnaire, representing each of the hamlets within the PNRC and all of the traditional socio-cultural activities in the Camargue (Table 1). 
Table 1. Socio-demographic information of the sample population for the study of the values associated with Greater flamingos in the Camargue, southern France.

\begin{tabular}{lcc}
\hline Variable & Total N & Total \% \\
\hline Gender & & \\
Male & 41 & $53 \%$ \\
Female & 46 & $47 \%$ \\
Age & 1 & \\
$<18$ & 4 & $1 \%$ \\
$18-24$ & 23 & $5 \%$ \\
$25-39$ & 52 & $26 \%$ \\
$40-64$ & 6 & $60 \%$ \\
$65-79$ & 1 & $7 \%$ \\
$\geq 80$ & 10 & $1 \%$ \\
Primary residence & 4 & $11 \%$ \\
Salin-de-Giraud & 5 & $5 \%$ \\
Le Sambuc & 3 & $6 \%$ \\
Gimeaux & 3 & $3 \%$ \\
Albaron & 25 & $3 \%$ \\
Mas Thibert & 6 & $29 \%$ \\
Arles & 19 & $7 \%$ \\
Towns around Arles & 8 & $22 \%$ \\
Other towns in southern France & 3 & $9 \%$ \\
Other towns in France & & $3 \%$ \\
Other countries & 5 & \\
Activity in Camargue & 2 & $6 \%$ \\
Rice farming & 2 & $2 \%$ \\
Cattle raising & 3 & $2 \%$ \\
Other Agriculture & 2 & $3 \%$ \\
Salt working & 6 & $2 \%$ \\
Hunting & 16 & $7 \%$ \\
Fishing & 19 & $18 \%$ \\
Tourism & 24 & $22 \%$ \\
Environmental management "managers" & & $28 \%$ \\
Environmental research "scientists" & & \\
\hline & &
\end{tabular}

Some of the participants in the survey did not live in the Camargue, but are considered Camargue stakeholders because they have some type of geographical connection (work, use, leisure, land ownership) to the territory.

\section{Survey questionnaire design}

The survey questionnaire was developed to capture the perceptions and the acceptance of management strategies in the Camargue. It included a total of 20 questions from which 69 different variables could be extracted. In the first section we retrieved socio-demographic information through nine structured questions (geographic identity, professional sector, employment position, gender and age) providing a description of the sampled population. The second section (4 structured questions) sought to deter-mine the level of knowledge of the participants concerning flamingo biology ("Where do flamingos breed in France?" and "How long can a flamingo live in the wild?"). This section examined correspondence between the level of knowledge and the per-ception of flamingo management in the Camargue as recommended by Hunter and Brehm (2004). The third section (7 structured and semi-structured questions) gathered information on the perceptions about flamingos in Camargue and the current man-agement strategies in the delta. 
A 5 point Likert Scale (strongly disagree, disagree, don't know, agree and strongly agree) (Sarantakos 2012) was used to rate the level of agreement of current manage-ment strategies of the PNRC as related to environmental, economic and social pillars of sustainable development (Wardell-Johnson et al. 2012). The activities in the environmental pillar included biodiversity, flamingo breeding, environmental tourism and waterbird presence. The economic pillar included tourism and cattle, rice, wine and other agricultural production. The social pillar included traditional cultural activities linked to bulls (bull fighting, bull races) and outdoor recreational activities (hiking, bird watching, etc.). The same Likert Scale was used to rate the importance of flamingo breeding sites in the Camargue. An open-ended question at the end of the survey aimed to identify the perceived threats to flamingos in the Camargue.

The survey results and possible future scenarios were presented to two advisory panel commissions (Agriculture and Natural Areas) of the PNRC. The members of the commissions are volunteers and participate over a 5-year period. At the time of the presentation to the advisory panels, the members of the commissions had already served for at least 3 years (if not longer). Some of the members of the commissions responded to the questionnaire (through the internet). During this meeting, the participants were asked to brain-storm potential landscape management strategies using a round table approach (Clifford, French, and Valentine 2010) . The participants were encouraged to take into account both the actual perceptions and the possible future changes in the delta.

\section{Data analysis}

Survey analysis triangulated qualitative data analysis and standard descriptive statistics. Standard descriptive statistics were used to identify the participants' level of agreement with statements on management practices in the Camargue. The qualitative data on perceived threats to flamingos and landscape management was extracted by an auto-mated content analysis tool applying emergent clustering algorithms to identify and extract concepts from the text from which thematic maps were generated (Smith 2003). Concepts were identified through an analysis of frequency, as well as a comparison of phrases and words with similar use. The semantic mapping reduced the likelihood of introducing researcher assumptions and influences in the process (Smith and Humphreys 2006). Collections of concepts were depicted as themes to visually display the interconnectedness and co-occurrence of concepts (www.leximancer.com). This automated semantic mapping uncovers ontology and representational structures through an unsupervised process. The process reduces biases often found in manual coded analyses (Dann 2010) with extensive use and testing across a wide range of research domains.

\section{Results}

Participants demonstrated a good basic knowledge of flamingo biology, with $80 \%$ of the participants identifying the location of the flamingo breeding site (Table 2). Even if there were some general responses like "coastal lagoons" and the "Camargue," $66 \%$ of the respondents specifically cited the Fangassier Lagoon as the flamingo breeding 


\begin{tabular}{lcc} 
Response & Number & Percentage \\
\hline Fangassier Lagoon & 24 & $28 \%$ \\
Fangassier Lagoon and Aigues-Mortes & 24 & $28 \%$ \\
Camargue & 7 & $8 \%$ \\
Mediterranean lagoons & 5 & $5 \%$ \\
Incorrect response & 3 & $3 \%$ \\
No response & 24 & $28 \%$ \\
Total & $\mathbf{8 7}$ & $\mathbf{1 0 0 \%}$ \\
\hline
\end{tabular}

\section{Flamingos need to breed in the Camargue.}

\section{Flamingos need to breed in}

Figure 2. Percentage of participant's responses to the 5 point Likert Scale regarding the concern of participants on the importance of maintaining a flamingo population living and breeding in Camargue and/or at specific breeding sites.

site. Slightly less than the majority $(45 \%)$ had some basic knowledge on the flamingo life span. This knowledge was shared by the general public as the results did not change when scientists and conservation land managers were removed from the analysis.

The great majority $(85 \%)$ of the participants felt that it was important to maintain the flamingo population in the Camargue, with slightly fewer (78\%) expressing the importance that flamingos remain a breeding species in the Camargue. The participants expressed higher levels of agreement with maintaining flamingo breeding in Salin -de-Giraud (81\%) than in Aigues-Mortes (64\%; Figure 2). The general public and the "scientific" and "land manager" participants shared these perceptions.

In response to the question "Do the current management practices benefit the different acitivites of the Camargue?," the participants perceived the mangagement to favor activities in the social pillar followed by the biodiversity pillar and lastly the economic pillar (Figure 3). More than $50 \%$ of the participants expressed that the current management strategies were not beneficial to economic activities linked to cattle, rice, wine and other agricultural production.

The most common themes identified through the semantic mapping in the responses to the question "What are the most important threats for flamingos in the Camargue today?" were "BREEDING" (100\%), "WATER" (95\%), "WETLANDS" (52\%), and "POLLUTION" (9\%), with an overlap in the themes "WATER" and "WETLANDS." The concepts associated with the theme "BREEDING" were "water," "nesting" (42\%), "food" (33\%), "changes" (33\%), "management" (25\%), "quality" (25\%), and "water level" (25\%) . Examples of these concepts can be found in the following statements "decrease in the protection of breeding areas," "loss of a breeding site and reduction of wetlands," 


\section{Social pille}

\section{Bull activite}

\section{Outdoor activitiє}

\section{Environmental tourisı}

\section{Economic pilla}

Figure 3. Percentage of the participants who agree with the current sustainable development management strategies in the Camargue as expressed as individual activities and the pillars of sustainable development.

"agricultural changes," "changes in water levels in the wetlands" and "poor quality of water." The concepts linked to the theme "WATER" were "management" (58\%), "salinas" (58\%), "lagoons" (42\%), and "decrease" (25\%). These concepts were found in the statements "poor water management," "difficult to maintain the wetlands," and "reduc-tion or loss of the salinas." The concept linked to the theme of "POLLUTION" is "water" $(17 \%)$. This is evident in the statements: "contamination of the food chain" and "pollution in the water and sediments."

Following the presentation of the survey results to the PNRC advisory panel working groups, the following management changes were suggested according to priority level:

1) extend the management decisions to cover the entire territory (i.e.,: moving beyond the limits of the PNRC to correspond to the Camargue biosphere reserve) in order to overcome the administrative divides between the two breeding sites; 2) do not 
concentrate exclusively on the flamingo, but rather incorporate other species and types of biodiversity into communication tools; 3) create new access and visitor facilities to improve flamingo observations in their different habitats; 4) improve communication and awareness about flamingos in the Camargue with tourists and the local population; and 5) modify farming practices to reduce the risks of flamingo damage in rice fields.

\section{Discussion}

Using flamingos as a flagship species, we analyzed the perceptions of landscape management in the Camargue in a time of global change. The majority of the participants demonstrated a sound knowledge of the ecological needs of flamingos and could specify the name of the historical breeding place of the species. This reflects the social valuing of the Camargue for nature conservation. Media attention covering flamingos has made a contribution to this awareness with massive press releases every summer (Ernoul and Wardell-Johnson 2016). Despite high levels of knowledge concerning flamingos in Camargue, the advisory panels continue to prioritize further communi-cation and awareness-raising for both the local population and tourists. Considering the current knowledge of the participants, we would suggest that additional commu-nication should move beyond basic information on the species, to include more on the perceived threats to flamingos including the natural life cycle of the species and wetland dynamics. This information would address the perceived threats to this iconic species and help legitimize the current management strategies which aim at imple-menting adaptive management practices in the context of global change (Mathevet and Guillemain 2016).

Scientifically derived conservation measures are more likely to be perceived as legitimate if aligned with perceptions of value within the local community of their application (Kim, Steiner, and Mueller 2011) . Perceptions of threats to flamingos are important to planning both communication strategies and conservation actions. In our study, participants acknowledged the importance of wetlands, salinas and lagoons for flamingos, but also expressed their concern over the changes in agricultural prac-tices and water management strategies for both quality and quantity of water circu-lating in the Camargue. The PNRC advisory panels' recommendations highlighted the need to modify farming practices and farm landscape to reduce the recurring problem of flamingo incursions, thus addressing the economic pillar of sustainable management. This need to address the economic sector can also be seen in previous studies on values mapping in the Camargue showing a geographic imbalance between economic gain and economic loss due to flamingos in the Camargue (Ernoul et al. 2018). However, according to our survey, there is high concern about water quality and quantity and this is often linked to agricultural production (Comoretto, Arfib, and Chiron 2007). Flamingos as a flagship species could be used to communicate on these issues, advocating change and legitimizing management decisions such as increas-ing local incentives for a transition to organic farming.

Public support for the management policies chosen by the PNRC was good as shown by the overall agreement $(>50 \%)$ for the current management policies for bio-diversity, flamingo breeding and tourism. However, there were lower levels of agreement $(<50 \%)$ for the management of the economic activities, especially for agricultural 
activities, with many participants stating that there is not enough support for economic development. Given the principal economic activities in the Camargue (agriculture, hunting, tourism and scientific research), it is important to consider the impact of the various management options on these sectors. It is essential that the management bodies take into account that the lower levels of agreement concerning economic activities may impact the local population's acceptance of conservation strategies (Bennett and Dearden 2014). Giving more importance to the economic pillar and specifically agricultural activities may create higher levels of acceptance of the managing body; however, this could also have an impact on the environment, effecting the fla-mingo population. As sustainable development is a compromise between the three pillars, it is essential to increase information sharing and collective work to adapt economic activities that are coherent with biodiversity constraints and biodiversity activities that are compatible with economic constraints.

The sampling methodology used in this study allowed us to have an overview of the perceptions of a wide range of stakeholders in and around the Camargue. It is however recommended that a more detailed questionnaire with a larger sample size be developed to ascertain the results and fine tune the suggestions concerning the communication strategy and management actions recommended as the result of this research.

\section{Conclusion}

We showed that focusing on flamingos as a flagship species could be a useful tool for generating interest and engagement with the local population and questioning more largely landscape management and planning policies. Flamingos, as a flagship species, may provide not only meaningful incentives but also to facilitate the identification of socioecological interdependence and full integration in decision-making systems (Mathevet et al. 2016). Nevertheless, as Cisneros-Montemayor and Vincent (2016) have highlighted, an emphasis on flagship species as drivers for management action can undervalue other pressing issues and may prove problematic for conservation efforts on the whole. In order to achieve successful conservation of wetlands and landscapes, inclusive and integrated approaches must be implemented.

This research demonstrates how socio-cultural variables can be incorporated into landscape planning and management (Wardell-Johnson 2007; Wardell-Johnson 2011). The understanding and acknowledgment of local perceptions is important to increase coastal landscape management legitimacy. Flagship species can be used as an effective tool to open dialogue with the local community about conservation and management practices. In addition, local communities are able to demonstrate their knowledge about conservation, and ensure parsimonious practices linking local with scientific knowledge.

\section{Funding}

This study was funded by the Fondation de France, Fondation MAVA and Fondation Tour du Valat. We thank Tatiana Fuentes, Katia Lombardini and Camille Muranyi-Kovacs for their support in the participatory workshops. 


\section{References}

Béchet, A., A. Arnaud, C. Germain, and A. Johnson. 2009. Greater Flamingos stop breeding in the Camargue (Souther France) in 2007, for the first time in 38 years; the beginning of a new era? In Flamingo, Special Publication 1:26-9. Flamingo. Antequera, Spain: IUCN-SSC/Wetlands International Flamingo Specialist Group. http://digital.csic.es/ handle/10261/61747

Béchet, A., and A. Johnson. 2007 . Anthropogenic and environmental determinants of greater flamingo phoenicopterus roseus breeding numbers and productivity in the Camargue (Rhone Delta, Southern France). Ibis 150 (1):69-79. doi: 10.1111/j.1474-919X.2007.00740.x.

Béchet, A., M. Rendon-Martos, M. Á. Rendon, J. A. Amat, A. R. Johnson, and M. Gauthier-Clerc. 2012. Global economy interacts with climate change to jeopardize species conservation: The case of the greater flamingo in the Mediterranean and West Africa. Environmental Conservation 39 (1):1-3. doi: 10.1017/S0376892911000488.

Bennett, N. J., and P. Dearden. 2014. Why local people do not support conservation: commu-nity perceptions of marine protected area livelihood impacts, governance and management in Thailand. Marine Policy 44:107-16. doi: 10.1016/j.marpol.2013.08.017.

Cisneros -Montemayor, A. M., and A. C. Vincent. 2016. Science, society, and flagship species: Social and political history as keys to conservation outcomes in the Gulf of California. Ecology and Society 21 (2) doi: 10.5751/ES-08255-210209.

Clifford, N. J., S. French, and G. Valentine, eds. 2010. Key methods in geography. 2nd ed. Thousand Oaks, CA: Sage Publications. p 549.

Comoretto, L., B. Arfib, and S. Chiron. 2007. Pesticides in the Rhône River Delta (France): Basic data for a field-based exposure assessment. The Science of the Total Environment 380 (1-3):124 32. doi: $10.1016 /$ j.scitotenv.2006.11.046.

Dann, S. 2010. Redefining social marketing with contemporary commercial marketing definitions. Journal of Business Research 63 (2):147-53. doi: 10.1016/j.jbusres.2009.02.013.

Ducarme, F., G. M. Luque, and F. Courchamp. 2013. What are 'charismatic species' for conservation biologists. BioSciences Master Reviews 10 (2013):1-8.

Ernoul, L., F. Mesléard, and A. Béchet. 2012. Diagnostic de l'échec de la contractualisation des mesures agri- environnementales pour réduire les incursions des flamants dans les Rizières de Camargue (France). VertigO 12 (1):10. doi: 10.4000/vertigo.12112.

Ernoul, L., F. Mesléard, P. Gaubert, and A. Béchet. 2014. Limits to agri-environmental schemes uptake to mitigate human-wildlife conflict: Lessons learned from flamingos in the Camargue, Southern France. International Journal of Agricultural Sustainability 12 (1):23-36. doi: 10.1080/14735903.2013.798897.

Ernoul, L., and A. Wardell -Johnson. 2014 . Adapting international conservation strategies to local context: Perceptions of biodiversity values and management responsibility in two med-iterranean deltas. International Journal of Biodiversity Science, Ecosystem Services \& Management 10 (4):300-12. doi: 10.1080/21513732.2014.980849.

Ernoul, L., and A. Wardell-Johnson. 2015. Environmental discourses: Understanding the implications on ICZM protocol implementation in two mediterranean deltas. Ocean \& Coastal Management 103:97-108. doi: 10.1016/j.ocecoaman.2014.11.014.

Ernoul, L., and A. Wardell- Johnson. 2016. Representing the greater flamingo in Southern France: A semantic analysis of newspaper articles showing change over time. Ocean \& Coastal Management 133:105-13. doi: 10.1016/j.ocecoaman.2016.09.015.

Ernoul, L., A. Wardell-Johnson, L. Willm, A. Béchet, O. Boutron, R. Mathevet, S. Arnassant, and A. Sandoz. 2018. Participatory mapping: Exploring landscape values associated with an iconic species. Applied Geography 95:71-78. doi: 10.1016/j.apgeog.2018.04.013.

European Union. 2009. Directive 2009/147/EC of the Eruopean Parliment and of the Council on the Conservation of Wild Birds. http://eur-lex.europa.eu/legal-content/EN/TXT/ $\mathrm{PDF} /$ ?uri=CELEX:32009L0147\& from=EN.

Guillemain, M., C. A. Pernollet, G. Massez, F. Cavallo, G. Simon, and J. Champagnon. 2015. Disentangling the drivers of change in common teal migration phenology over 50 years: 
Land use vs. climate change effects. Journal of Ornithology 156 (3):647-55. doi: 10.1007/ s10336-015-1171-z.

Hunter, L. M., and J. M. Brehm. 2004. A qualitative examination of value orientations toward Wildlife and biodiversity by rural residents of the intermountain region. Human Ecology Review $11(1): 13-26$.

Johnson, A., and F. Cézilly. 2007. The greater flamingo. London, UK: T\&A Poyser. T \& AD Poyser.

Kahila, M., and M. Kyttä. 2009. SoftGIS as a bridge-builder in collaborative urban planning. In Planning support systems best practice and new methods, 389-411. Dordrecht: Springer. http://link.springer.com/chapter/10.1007/978-1-4020-8952-7_19.

Kim, J. O., F. Steiner, and E. Mueller. 2011. Cranes, crops and conservation: Understanding human perceptions of biodiversity conservation in South Korea's civilian control zone. Environmental Management 47 (1):1-10. doi: 10.1007/s00267-010-9568-1.

Maris, V., and A. Bechet. 2010. From adaptive management to adjustive management : A pragmatic account of biodiversity values. Conservation Biology 24 (4):966-73. doi: 10.1111/j.15231739.2009.01437.x.

Mathevet, R., C. Tourenq, and F. Mesléard. 2002. Agricultual policies, land -use and water-bird conservation: The case study of a major mediterranean wetland, the Camargue. Cybergeo, the European Journal of Geography (221). http://cybergeo.revues.org/3755?lang= fr\&file=1.

Mathevet, R., 2004. Camargue incertaine: Sciences, usages et natures, Buchet-Chastel Editions. ed. Paris.

Mathevet, R., and M. Guillemain. 2016. Que ferons-nous des canards sauvages?: Chasse, nature et gestion adaptative. Arles, France: Editions Quae.

Mathevet, R., J. D. Thompson, C. Folke, and F. Stuart Chapin. 2016. Protected areas and their surrounding territory: Socioecological systems in the context of ecological solidarity. Ecological Applications 26 (1):5-16. doi: 10.1890/14-0421.

Pernollet, C. A., A. Guelmami, A. J. Green, A. Curcó Masip, B. Dies, G. Bogliani, F. Tesio, A. Brogi, M. Gauthier-Clerc, and M. Guillemain. 2015. A comparison of wintering duck num-bers among European rice production areas with contrasting flooding regimes. Biological Conservation 186:214-24. doi: 10.1016/j.biocon.2015.03.019.

Runge, C. A., J. C. Withey, D. E. Naugle, J. E. Fargione, K. J. Helmstedt, A. E. Larsen, S. Martinuzzi, and J. D. Tack. 2019. Single species conservation as an umbrella for management of landscape threats. PLoS One 14 (1):e0209619. doi: 10.1371/journal.pone.0209619.

Sarantakos, S. 2012. Social research. 4th ed. South Melbourne: Palgrave Macmillan.

Senzaki, M., Y. Yamaura, Y. Shoji, T. Kubo, and F. Nakamura. 2017. Citizens promote the conservation of flagship species more than ecosystem services in wetland restoration. Biological Conservation 214:1-5. https://agris.fao.org/agris-search/search.do?recordID=US201800027323. doi: 10.1016/j.biocon.2017.07.025.

Shen, X., S. Li, W. J. McShea, D. Wang, J. Yu, X. Shi, W. Dong, X. Mi, and K. Ma. 2020. Effectiveness of management zoning designed for flagship species in protecting sympatric species. Conservation Biology 34 (1):158-67. doi: 10.1111/cobi.13345.

Smith, A. E. 2003. Automatic extraction of semantic networks from text using Leximancer. 23-24. doi: 10.3115/1073427.1073439.

Smith, A. E., and M. S. Humphreys. 2006. Evaluation of unsupervised semantic mapping of natural language with Leximancer concept mapping. Behavior Research Methods 38 (2):262- 79. doi: $10.3758 / \mathrm{bf03192778.}$

Smith, A. M., and S. G. Sutton. 2008. The role of a flagship species in the formation of conservation intentions. Human Dimensions of Wildlife 13 (2):127-40. doi:10.1080/ 10871200701883408.

Turner, M. G. 2010. Disturbance and landscape dynamics in a changing world. Ecology 91 (10):2833-49. doi: 10.1890/10-0097.1. 
Wardell-Johnson, A. 2007. People in context: Critical social dimensions in complex landscape systems. Doctor of philosophy in Environmental sociology. Western Australia: Murdoch University.

Wardell-Johnson, A. 2011. Value connections between people and landscapes. In Biodiversity \& social justice: Practices for an ecology of peace, 15-29. Perth, Western Australia: Black Swan Press.

Wardell-Johnson, A., N. Islam, T. Nath, and S. Biziak. 2012. The future of food: The triple bottomline, expert opinion and a world class food system. The International Journal of Environmental, Cultural, Economic and Social Sustainability 7. 